\title{
LA RESPONSABILIDAD POR LOS DAÑOS CAUSADOS POR PRODUCTOS DEFECTUOSOS: AsPECTOS DE DERECHO FRANCÉS*
}

\section{Responsibility for Damages Caused by Defective Products: French RIGHTS ASPECTS}

Julien Couard

Trabajo recibido 27 de diciembre de 2017 y aprobado el 28 de septiembre de 2018

\section{Resumen}

En el presente trabajo el autor desarrolla en términos sintéticos el panorama del derecho francés acerca de la responsabilidad por los daños causados por los productos defectuosos. Concluye que Francia tiene un régimen equilibrado entre los intereses de seguridad jurídica del productor y de protección e indemnización de los usuarios de productos, que permitió liberarse de las dudas nacidas con el tiempo a propósito de los textos originales del Código civil, pero sin abolirlos, al conservar todavía toda su utilidad.

Palabras Claves: daños, productos defectuosos, responsabilidad civil.

\begin{abstract}
In the present paper, the author develops in synthetic terms the panorama of French law regarding liability for damages caused by defective products. It concludes that France has a balanced regime between the interests of legal certainty of the producer and protection and compensation of users of products that allowed to get rid of the doubts born over time with regard to the original texts of the Civil Code, but without abolishing them, still retain all its usefulness.
\end{abstract}

Key words: damage, defective products, civil liability.

\section{INTRODUCCIÓN}

El desarrollo del derecho del consumo por la ley o la jurisprudencia, a partir del decenio de 1980, aumentó significativamente las posibilidades de hacer efectiva la responsabilidad de los profesionales. Así, por ejemplo, surgió la responsabilidad del profesional en materia alimentaria, bancaria, inmobiliaria, de información, de advertencia, de sobreendeudamiento etc.'

1 V. por ejemplo, G. VINEY et P. JOURDAIN, Les régimes spéciaux et l'assurance de responsabilité, 4 4ème éd., LGDJ, Traité de droit civil (J. Ghestin, dir.), nov. 2017,688 p. y de los mismos autores, Les effets de la responsabilité, 4 ème éd., LGDJ, Traité de droit civil (J. Ghestin,

\footnotetext{
* Julien Couard, Doctor en Derecho, Maître de conférences HDR, Universidad de Toulon, Centre de droit et de politique comparés (UMR CNRS 7318 DICE),Toulon, Francia. Correo de contacto, julien.couard@univ-tln.fr. Dirección postal: 35, avenue Alphonse Daudet, Bp 1406, 83056, Toulon, Cedex, Francia.
} 
Sin embargo, la tendencia fundamental de este desarrollo está consagrada por el régimen de responsabilidad relativa a los productos defectuosos, que se puede considerar como un tipo de síntesis de lo que está en juego en torno del vínculo entre responsabilidad y derecho de consumo.

Pero, en el mismo tiempo, en Francia, este régimen constituye una excepción a la tendencia más global a la especialización del derecho del consumo.

De conformidad con los actuales artículos 1245 y siguientes del Código civil francés relativos a la responsabilidad por los daños causados por productos defectuosos, los productores son responsables de estos productos en todas las situaciones, con o sin contractos, cuando el producto ha causado daños personales o materiales. Es decir que tenemos aquí un régimen de responsabilidad por determinación de la ley que no se refiere a la distinción clásica entre responsabilidad contractual y responsabilidad extracontractual.

Esta evolución de la legislación francesa viene de la transposición de la Directiva (85/374/CEE) del 25 de julio de 1985 por la ley del 19 de mayo de $1998^{2}$.

Entonces, han transcurrido nada más que trece años antes de que Francia transpuso la directiva. De hecho, fue condenada en 1993 por incumplimiento de sus obligaciones ${ }^{3}$.

¿Por qué esta resistencia del legislador y su respuesta tardía para transponer la directiva? Tenemos dos razones a esto.

Primera, el sentimiento de buena aplicación del derecho existente: La certeza del carácter perfecto de las disposiciones del código de 1804, adecuadas para regir todas las situaciones particulares. Segunda, más prosaica, la presión de los industriales para conservar un régimen que se presentaba como favorable para ellos.

Así, en caso de daño nacido del defecto de un producto, distinguíamos dos situaciones.

La víctima disponiendo de un contrato con el productor o el vendedor, podía actuar con arreglo a las disposiciones sobre la garantía del vicio oculto (redhibitorios) ${ }^{4}$, dicho de otro modo, por defectos latentes, la que no era su finalidad (que es de remediar la falta de utilidad de la cosa vendida). Debía pues, producir la prueba de la existencia del vicio y de su carácter oculto o latente: "probatio diabólica" porque a menudo resultaba imposible de practicar.

La víctima no disponiendo de un contrato, debía actuar con arreglo a las disposiciones sobre la res-

dir.), mai 2017, 880 p.; Ph. BRUN, Responsabilité civile extracontractuelle, 4 ème éd., Lexis Nexis, coll. Manuels, nov. 2016,674 p.; Ph. Le TOURNEAU (dir.), Droit de la responsabilité et des contrats, 11 ème éd., Dalloz Action, nov. 2017, 2760 p.; M. BACACHE-GIBEILI, Les

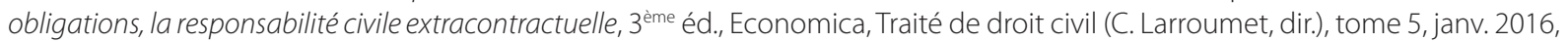
$1104 \mathrm{p}$.

2 J. GHESTIN, «Le nouveau Titre IV bis du Libvre III du Code civil «De la responsabilité du fait des produits défectueux». L'application en France de la directive sur la responsabilité du fait des produits défectueux après la loi n98-389 du 19 mai 1998 », JCP G 1998, I, 148; G. VINEY, «L'introduction en droit français de la directive européenne du 25 juillet 1985 relative à la responsabilité du fait des produits défectueuX», rec. Dalloz 1998, 291; P. JOURDAIN, «Commentaire de la loi n98-389 du 19 mai 1998 sur la responsabilité du fait des produits défectueuX», JCP E 1998, 1204; Y. DAGORNE-LABBE, «La loi du 19 mai 1998 relative à la responsabilité du fait des produits défectueuX», Defrénois 1998, 1265; G. RAYMOND, «Premières vues sur la loi n98-389 du 19 mai 1998 sur la responsabilité du fait des produits défectueux», Contrats, conc., consom. 1998, chronique n7; C. LARROUMET, «La responsabilité du fait des produits défectueux après la loi du 19 mai 1998», rec. Dalloz 1998, 311.

3 CJCE, 25 avril 2002, Commission des Communautés Européennes contre République française, affaires jointes C-52/00, C-154/00 C-183/00; Contrats, conc., consom. 2002, n¹1, p. 4-5, obs. C. LAPORTE; A. CHAMBRAUD, «La difficile introduction de la directive sur la responsabilité du fait des produits défectueux en droit français», Rev. europ. dr. de la consommation, 1997/3, p. 169. 4 Art. 1641 C. civ.

COUARD, JULIEN. La responsabilidad por los daños causados por productos defectuosos: Aspectos de derecho francés. Revista Justicia y Derecho, Santiago, v. 1, n 1, 2018 
ponsabilidad extracontractual ${ }^{5}$, enfrentándose a dos obstáculos: uno clásico, el problema de la prueba de la falta del productor o del vendedor, casi imposible de practicar; y el otro relacionado con la cuestión de las cosas de las que se tiene a la guardia, más eficiente pues no es necesario probar una falta sino la guarda o custodia de la cosa por la víctima ${ }^{6}$. Entonces, la diferencia de naturaleza entre los dos tipos de responsabilidad, que hace imposible la acumulación entre ellas, no permitía a la víctima parte de un contrato, actuar con el régimen favorable de responsabilidad a causa de su carácter de custodio de las cosas bajo su guarda.

Podemos ver que el sistema funcionaba, pero era necesario librarse de barreras de la prueba de la falta y de la existencia o no de un contrato.

La filosofía del texto de 1998 fue de conducir a una mayor protección de las víctimas, bajo la influencia lejana pero efectiva del derecho norteamericano que ha consagrado, desde los años 60, el concepto de «strict liability in torts», el cual permite la reparación de los daños causados por productos ${ }^{7}$. Sin embargo, el texto se basa también sobre una justificación de orden económica, especialmente la del buen funcionamiento del mercado único europeo cuyo fundamento es consumista antes de todo.

Además, es interesante anotar que el margen de los Estados-miembros de la Unión Europea es estrecho desde que la Corte de Justicia de la Unión, por tres sentencias del 25 de abril de 2002, pronunció que la directiva había producido de plena armonización de los derechos entre los Estados-miembros ${ }^{8}$. Es decir que, hoy, tenemos un régimen de responsabilidad casi igual en toda la Unión Europea?.

En Francia, la reforma del régimen general del derecho de las obligaciones por la ordenanza del 10 de febrero de 2016, no ha modificado, en el Código civil, el contenido ni la formulación de los artículos sobre la responsabilidad incluidos en 1998, solo su numeración (ex art. 1386-1 et s.) ${ }^{10}$. Pero, a diferencia de códigos civiles de muchos países de América del Sur, que no contienen disposiciones sobre la responsabilidad por los daños causados por productos defectuosos, la presencia de este régimen en el Código civil francés no ocurre por sí solo. La intención del legislador, la ratio legis, fue de mostrar la dimensión general del texto y no solo sus características de derecho del consumo.

Entonces podemos decir que el régimen actual intenta responder a un reto y posee una tendencia. Un reto que es el ámbito de aplicación muy general (I), y una tendencia que es la indemnización del usuario (II).

\footnotetext{
5 Art. 1240 y siguientes (ex art. 1382 y sig.) C. civ.

6 A proposito de la guardia, ver Cass. ch. réunies, 2 déc. 1941, rec. Dalloz critique 1942, 25, rapport LAGARDE et note G. RIPERT; rec. Sirey 1941, I, 217, note L. MAZEAUD; JCP 1942, II, 1766, note J. MIHURA; H. CAPITANT, F. TERRÉ et Y. LEQUETTE, Grands arrêts de

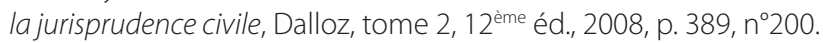

7 Ver por ejemplo, R. A. EPSTEIN, Theory of Strict Liability: Toward a Reformation of Tort Law, Cato Institute, 1979, p. 141.

8 CJCE, 25 de april de 2002, antedicho.

9 J.-S. BORGHETTI, La responsabilité du fait des produits défectueux, Etude de droit comparé, LGDJ, Bibl. de droit privé, tome 428 , 2004, 784 p.; P. JOURDAIN et A. GUEGAN-LECUYER (dir.), «La responsabilité du fait des produits défectueux, 30 ans après la directive», rev. Resp. civ. et assur. 2016, dossier spécial.

10 Ord. n²016-131 du 10 février 2016 portant réforme du droit des contrats, du régime général et de la preuve des obligations, Journal officiel du 11 févr. 2016, texte n³6: podrá consultarse en línea en el sitio web Légifrance; adde, Fr. TERRÉ (dir.), Pour une réforme du droit de la responsabilité civile, Dalloz, coll. Thèmes et commentaires, nov. 2011, 238 p.; M. MEKKI (coord.), Avant-projet de réforme du droit de la responsabilité civile: l'art et la technique du compromis, Lextenso, nov. 2016, 186 p.; M. LATINA et G. CHANTEPIE, La réforme du droit des obligations - Nouveauté: Commentaire théorique et pratique dans l'ordre du Code civil, DaIlOz, juin 2016, 1104 p.; Y.-M. LAITHIER, T. GENICON et O. DESHAYES, Réforme du droit des contrats, du régime général et de la preuve des obligations: Commentaire article par article, Lexisnexis, oct. 2016, 945 p.; B. MERCADAL, Réforme du droit des contrats, éd. Francis Lefebvre, mai 2016, 408 p.
} 


\section{UN RETO: EL ÁMBITO DE APLICACIÓN MUY GENERAL}

El artículo 1245 del Código civil francés dispone que «El productor se responsabilizará del daño causado por un defecto de su producto, esté o no vinculado a la víctima por un contrato». Así podemos ver que este texto que introduce la responsabilidad derivada de productos defectuosos es de aplicación muy general en cuanto a las orígenes del daño (A) y en cuanto a las personas concernidas (B).

\subsection{En cuanto a los orígenes del daño}

La primera condición de aplicación de la ley es que el daño invocado debe tener su origen en el defecto de un producto puesto en circulación, lo que conduce a estudiar primero el concepto de producto puesto en circulación (1.1) y luego, el concepto de defecto (1.2).

\subsubsection{El concepto de producto puesto en circulación}

El concepto de producto puesto en circulación pone en tela de juicio el significado preciso de las nociones de producto (a) y de puesta en circulación (b).

\subsubsection{El producto}

El artículo 1245-2 del Código civil afirma que «se entiende por producto cualquier bien mueble, aunque esté incorporado a un inmueble, con inclusión de los productos de la tierra, la ganadería, la caza y la pesca». Añade que «la electricidad se considerará un producto».

Es decir, que la noción de producto aquí es muy larga: solo los edificios (inmuebles) escapan el texto; por analogía o referencia a otros textos, los productos del cuerpo humano, los gases, los medicamentos son productos. Por otra parte, los medicamentos representan un problema a causa del tiempo a veces muy largo entre el momento del consumo y el daño que, además, puede producirse sobre otra persona como, por ejemplo, niños ${ }^{11}$.

Sin embargo, a pesar de esta concepción muy amplia del producto, no debemos olvidar la segunda condición de su puesta en circulación.

\subsubsection{La puesta en circulación}

La puesta en circulación se entiende cuando el productor se haya desprendido de su producto voluntariamente ${ }^{12}$. La ley establece que un producto solo puede ser objeto de una única puesta en circulación.

El desapoderamiento del producto debe tener como finalidad la venta o cualquier otra forma de distribución. Es decir que el productor no asume la responsabilidad en cuanto a los productos que todavía

11 L. CLERC-RENAUD, «Quelle responsabilité en cas de dommages causés par des produits de santé?», RLDC 2007/1, p. 15; M. BORGETTO et alii, «La responsabilité du fait des produits de santé défectueuX», RDSS 2008, p. 1005.; L. BLOCH, «Pour une autre présentation de responsabilité du fait des produits de santé défectueux», rev. Resp. civ. et assur. 2009/12, p. 7; acercar, V. BOUQUET et E. FOUASSIER, «Le projet de réforme de la responsabilité civile et les produits de santé», rec. Dalloz 2017, 834; Cass. civ. 1ère, 20 sept. 2017, n¹6-19643; JCP G 2017, 1186, note J.-S. BORGHETTI; Cass. civ. 1 ${ }^{\text {rè }}, 18$ oct. 2017, n¹5-20791; JCP G 2017, 1220, note G. VINEY.

12 J.-Ph. CONFINO, «La mise en circulation dans la loi du 19 mai 1998 sur la responsabilité du fait des produits défectueux», Gaz. Pal., 2 févr. 2001, n³3, p. 2 et 22 avr. 2001, n¹12, p. 2; CJCE, 9 févr. 2006, O’Byrne, rev. europ. dr. de la consommation, 2005/4, p. 352, note V. PIRE; JCP G 2006, I, 166, n¹4, obs. Ph. STOFFEL-MUNCK; rec. Dalloz 2006, 1934, obs. Ph. BRUN.

COUARD, JULIEN. La responsabilidad por los daños causados por productos defectuosos: Aspectos de derecho francés. Revista Justicia y Derecho, Santiago, v. 1, n 1, 2018 
están bajo su control y no ofrecidos para la venta. No asume también el defecto de un producto robado ni transmitido a fines de ensayo, de estudio (como prototipos, moldes o modelos) o de destrucción (si son desechos o residuos, por ejemplo).

La puesta en circulación constituye realmente el hecho generador de la responsabilidad. Es a partir de ella que corre el plazo de prescripción de la acción en responsabilidad ${ }^{13}$.

No obstante, el texto existente no resuelve totalmente ciertos problemas. ¿Respecto al criterio de única puesta en circulación, cuál es la situación, por ejemplo, de productos incorporados a otros? ¿Hay que contar una puesta en circulación con cada incorporación o solo con la comercialización del producto final? ¿En consecuencia, cuantos responsables hay: uno, el productor final, o todos los que han incorporado sus productos al producto final? La ley no lo dice.

¿Por otra parte, qué sucede con los productos producidos en serie? ¿Debemos tener en cuenta como hecho generador de la responsabilidad, el momento de la primera puesta en circulación o el momento de la puesta en circulación del producto defectuoso que sea la causa del daño? Aquí tampoco, la ley dice algo. Pues, los autores han sugerido distinguir según que el defecto viene de la concepción o de la fabricación del producto. Si viene de la concepción, será preferible adoptar el momento de la primera puesta en circulación. Si no, la puesta en circulación del producto defectuoso será retenida como punto de partida de la prescripción ${ }^{14}$.

\subsubsection{El concepto de defecto}

El segundo criterio de la responsabilidad por los daños causados por productos, depende del concepto de defecto del producto.

Según la ley, un producto será defectuoso «cuando no ofrezca la seguridad que cabe legítimamente esperar de él»15. «En la apreciación de la seguridad que cabe legítimamente esperar, deberán tenerse en cuenta todas las circunstancias y, en particular, la presentación del producto, el uso que pueda esperarse razonablemente de él y el momento de su puesta en circulación» ${ }^{16}$.

Aquí, la jurisprudencia es muy atenta a «la presentación del producto», especialmente a las advertencias necesarias a su utilización ${ }^{17}$.

Además, el tiempo es un criterio fundamental.

Todavía, según la ley, «un producto no podrá considerarse defectuoso por el solo hecho de que, posteriormente, se haya puesto en circulación otro más perfeccionado» ${ }^{18}$. Esta precisión manifiesta la preocupación de no desalentar los avances tecnológicos: la obsolescencia no es un defecto del producto ${ }^{19}$.

Es importante destacar que es al «momento de su puesta en circulación» que se considerará el de-

13 Ph. STOFFEL-MUNCK, JCP G 2007, I, 185; Cass. civ. 1 ère, 24 janv. 2006, n03-20.178; JCP G 2006, II, 10082, note L. GRYNBAUM; JCP G 2006, l, 166, n4, obs. Ph. STOFFEL-MUNCK; rec. Dalloz 2006, 1931, obs. P. JOURDAIN; RDC 2006, 841, obs. J.-S. BORGHETTI; RTD civ. 2006, 323, obs. P. JOURDAIN.

14 Ph. BRUN, Responsabilité civile extracontractuelle, ob. cit., n743.

15 Art. 1245-3 C. civ.

16 Idem.

17 Ver, por ejemplo, Cass. civ. 1ère, 5 avr. 2005, JCP G 2005, I, 149, n5, obs. G. VINEY; JCP G 2005, II, 10085, note L. GRYNBAUM; Cass. civ. 1ère, 21 juin 2005, Bull. civ. 2005, I, n²75; Cass. civ. 1 ère, 24 janv. 2006, Bull. civ. 2006, I, n³5; Cass. civ. $1^{\text {ère, }} 7$ nov. 2006, Bull. civ. 2006, I, n²67; Cass. civ. 1ère, 22 nov. 2007, JCP G 2008, I, 125, nº7, obs. Ph. STOFFEL-MUNCK.

18 Art. $1245-3$ al. 3 C. civ.

19 En este senso, L. LEVENEUR, «Le défaut», in «La responsabilité du fait des produits défectueux», Les Petites Affiches, 28 déc. 1998, numéro spécial, p. 28. 
fecto. El defecto posterior no será considerado ${ }^{20}$, como no serán considerados el uso no previsible normalmente del producto al momento de su puesta en circulación ${ }^{21}$ ni "el estado de los conocimientos científicos y técnicos"22 posteriores a la puesta en circulación.

Estas condiciones relativas al origen del daño son objetivas. Pero, la buena aplicación de la ley necesita interesarse en las personas.

\subsection{En cuanto a las personas}

En cuanto a las personas, hay que distinguir entre el productor y la víctima, que son los dos protagonistas del régimen de responsabilidad estudiado.

\subsubsection{El concepto de productor}

Con la definición del producto, podemos ver la evidente y estrecha referencia de la ley con el derecho del consumo. En efecto, «son productores, cuando actúen a título profesional, el fabricante de un producto acabado, el productor de una materia prima y el fabricante de un componente» ${ }^{23}$. A los efectos de la aplicación del texto, el legislador precisa que «se asimila a un productor a cualquier persona que, actuando a título profesional:

$1^{\circ}$ Se presente como productor estampando su nombre, marca u otro signo distintivo en el producto;

$2^{\circ}$ Importe un producto a la Comunidad Europea con la intención de venderlo, alquilarlo, con o sin pacto de venta, o distribuirlo de cualquier otra forma» ${ }^{24}$.

Es una forma de aplicación de la teoría de la apariencia.

A estas disposiciones, la ley añade una regla importante y subsidiaria: «cuando no sea posible identificar al productor, el vendedor, arrendador, [a excepción del arrendador financiero o del arrendador asimilable al arrendador financiero,] o cualquier otro proveedor profesional, se responsabilizarán de la falta de seguridad del producto en condiciones idénticas a las del productor, a menos que, en un plazo de tres meses tras la fecha en que se le diese traslado de la demanda de la víctima, designen a su propio proveedor o al productor» ${ }^{25}$.

Así, la categoría del productor parece muy larga.

Sin embargo, no se considerarán productores, en el sentido del texto, el vendedor de un inmueble por construir o el constructor de un edificio ${ }^{26}$, es decirir:

$1^{\circ}$ Cualquier arquitecto, empresario, técnico u otra persona vinculada al propietario de la obra en virtud de un contrato de arrendamiento de obra;

$2^{\circ}$ Cualquier persona que venda, tras su terminación, una obra que haya construido o hecho construir;

20 Art. 1245-10, $2^{\circ}$ C. civ.; Ph. BRUN, Responsabilité civile extracontractuelle, ob. cit., n741.

21 Art. 1245-3 al. 2 C. civ.

22 Art. $1245-10,4^{\circ} \mathrm{C}$. civ.

23 Art. 1245-5 C. civ.

24 Idem; concerniente la noción de importador, ver Cass. civ. 1 1ère, 4 juin 2014, n¹3-13.548 et n¹2-29.848; RDC 2014, 613, obs.

J.-S. BORGHETTI; Gaz. Pal. 2014, 24, obs. D. NOGUERO.

25 Art. 1245-6 C. civ.

26 Art. 1245-5 in fine C. civ.

27 Art. 1792 a $1792-6$ y $1646-1$ C. civ.

COUARD, JULIEN. La responsabilidad por los daños causados por productos defectuosos: Aspectos de derecho francés. Revista Justicia y Derecho, Santiago, v. 1, n 1, 2018 
$3^{\circ}$ Cualquier persona que, aunque actuase en calidad de mandatario del propietario de la obra, desempeñe una función asimilable a la de un contratista de obras.

Fuera de dichas excepciones, cualquier profesional es un productor y cualquier no profesional no puede ser calificado de productor: nos encontramos por tanto en una configuración de derecho del consumo aunque la ley esté presente en el Código civil28.

\subsubsection{El concepto de víctima.}

En realidad, esta presencia en el Código civil puede explicarse con relación a la víctima. En efecto, la ley no define a la víctima pero la interpretación de sus diferentes artículos conduce a considerar como víctima, toda persona natural o jurídica que sufra un daño en su ser o en sus bienes, a excepción del productor mismo ${ }^{29}$. Así, un profesional puede ser una víctima, como un consumidor.

Además, recordemos que ninguna importancia tiene la existencia de un contrato entre el productor y la víctima.

Sin embargo, si la ley será de aplicación a la reparación del daño que derive de cualquier atentado contra las personas, será asimismo de aplicación a la reparación de cualquier daño, pero por encima de un importe de 500 euros y solo por un atentado contra bienes diferentes del producto defectuoso ${ }^{30}$. Francia fue condenada por el incumplimiento de este umbral de aplicación no del régimen de responsabilidad del productor pero del régimen de la reparación previsto en la directiva europea ${ }^{31}$. Pues, desde 2005, esta franquicia existe y restringe, de facto, la categoría de las víctimas al sentido de las disposiciones sobre la reparación de los daños causados por productos defectuosos ${ }^{32}$. No obstante, la persona afectada podrá acogerse a los fundamentos de la responsabilidad civil clásica que es sin franquicia ${ }^{33}$.

Entonces, a pesar de la existencia de estas restricciones menores, el ámbito de aplicación muy general de la ley conduce a una tendencia que es la indemnización del usuario, de todos los usuarios.

\section{UNA TENDENCIA: LA INDEMNIZACIÓN DEL USUARIO}

Esa tendencia exige considerar la aplicación del régimen de responsabilidad en cuanto a la víctima (1) y en cuanto a los responsables (2).

\footnotetext{
28 Sólo el derecho del consumo pone la diferencia entre profesional y no profesional para introducir obligaciones a cargo del profesional y derechos por el no profesional. Tradicionalmente, el diseño civilista es un diseño igualitario entre los partes.

29 Por una interpretación amplia del concepto, ver Ph. BRUN, op. cit., n734, confirmada por CJCE, 4 juin 2009, aff. C-285/08, Moteurs Leroy Somer: JurisData $n^{\circ}$ 2009-007423; JCP G 2009, 82, P. JOURDAIN; RDC 2009, 1381, note G. VINEY; RDC 2009, 1448, note C. AUBERT DE VINCELLES; rec. Dalloz 2009, 1731, note J.-S. BORGHETTI; rec. Dalloz 2010, 49, obs. O. GOUT; RTD civ. 2009, p. 738, obs. P. JOURDAIN; adde, J. ROCHFELD, «Les ambiguïtés des directives d'harmonisation totale: la nouvelle répartition des compétences communautaire et interne (à propos de l'arrêt de la CJCE du 4 juin 2009)», rec. Dalloz 2009, 2047.

30 Art. 1245-1 al. 2 C. civ.

31 CJCE, 25 avr. 2002, aff. C-52/00, Commission c/ France, antes citado.

32 J. TRAULLÉ, «Responsabilité du fait des produits défectueux - Les dommages réparables», rev. Resp. civ. et assur. 2016, dossier 4.

33 Art. 1240 y ss. C. civ.
}

COUARD, JULIEN. La responsabilidad por los daños causados por productos defectuosos: Aspectos de derecho francés. Revista Justicia y Derecho, Santiago, v. 1, n 1, 2018 


\subsection{La aplicación en cuanto a la víctima.}

En cuanto a la víctima, es necesario tratar de los plazos para la presentación de demandas (1.1) y de la carga de la prueba (1.2).

\subsubsection{Los plazos de presentación de demandas.}

La ley establece un dispositivo original para demandar, con dos plazos de prescripción que se aplican simultáneamente ${ }^{34}$.

Así, la responsabilidad se extinguirá a los diez años de la puesta en circulación del producto que hubiese causado el daño ${ }^{35}$. Y en este período, la acción de reparación prescribirá en un plazo de tres años tras la fecha en que el demandante hubiese tenido o debiese haber tenido conocimiento del daño, del defecto y de la identidad del productor.

Quiere decir que por un producto puesto en circulación en 2010, si hay un defecto y un daño en 2015, la víctima podrá actuar hasta 2018.

Pero también, por un producto puesto en circulación en 2010, si hay un defecto y un daño en 2019, todavía en el plazo de diez años, la víctima podrá actuar hasta 2022.

Sin embargo, por el mismo producto, si hay un defecto y un daño en 2021, la víctima no podrá actuar porque su acción judicial estará prescrita.

\subsubsection{La carga de la prueba.}

Según la ley, «el demandante deberá probar el daño, el defecto y el vínculo de causalidad entre el defecto y el daño» ${ }^{36}$.

\subsubsection{Tipo de daño y tipo de reparación.}

Como ya hemos visto, el daño se irroga a alguien o a algo, a una persona o a sus bienes. Pues, puede ser corporal (moral o material) o económico: en este sentido, el ámbito de aplicación de la ley es muy amplia ${ }^{37}$. Sin embargo, la ley no prevé nada a propósito del modo de reparación. Por analogía con el régimen general, la indemnización consiste normalmente en el pago de una suma de dinero.

\subsection{Defecto.}

Si la víctima debe probar el defecto del producto, no tiene que probar la falta del productor ${ }^{38}$. Tratándose de un hecho, la prueba se hace por cualquier medio.

\subsection{Nexo causal.}

En cuanto al vínculo de causalidad entre el daño y el defecto, se remite a la posibilidad para el juez, de designar a un experto y, para el productor, a las causas de exoneraciones previstas por la ley.

34 S. JOLY, «La nouvelle génération des doubles délais extinctifs», rec. Dalloz 2001, chron. 1450.

35 Art. 1245-15 C. civ.

36 Art. 1245-8 C. civ.

37 J. TRAULLÉ, «Responsabilité du fait des produits défectueux - Les dommages réparables», antes citado.

38 Art. 1245-8 C. civ.; Ph. BRUN, ob. cit., n741.

COUARD, JULIEN. La responsabilidad por los daños causados por productos defectuosos: Aspectos de derecho francés. Revista Justicia y Derecho, Santiago, v. 1, n 1, 2018 
Por la jurisprudencia, una simple posibilidad de vínculo fundada sobre la verosimilitud de la relación entre el defecto y el daño, es suficiente para establecer la responsabilidad del productor ${ }^{39}$.

\subsection{La aplicación en cuanto a los responsables.}

En efecto, el productor es responsable de pleno derecho. A veces, por ejemplo en caso de daño causado por el defecto de un producto incorporado a otro, se responsabilizarán con carácter solidario el productor del componente y el que hubiese realizado la incorporación ${ }^{40}$.

Además, la víctima puede también prevalerse de la responsabilidad derivada de productos defectuosos y de la responsabilidad contractual o extracontractual: es, entonces, posible la acumulación ${ }^{41}$.

Por último, «se prohíben las cláusulas destinadas a descartar o limitar la responsabilidad derivada de los productos defectuosos, que se tendrán por no puestas» ${ }^{42}$.

Pero, la responsabilidad del productor puede reducirse o suprimirse según causas generales (2.1) o específicas (2.2) de exoneración.

\subsubsection{Las causas generales de exoneración.}

Las causas generales de exoneración como la fuerza mayor son admitidas en este régimen de responsabilidad especial. La ley establece que la responsabilidad del productor podrá reducirse o suprimirse, teniendo en cuenta todas las circunstancias, cuando el daño hubiese sido causado conjuntamente por un defecto del producto y por la falta de la víctima o de una persona de la que esta sea responsable ${ }^{43}$.

Sin embargo, «la responsabilidad del productor ante la víctima no se verá reducida por el hecho de que un tercero hubiese concurrido a la realización del daño» ${ }^{44}$.

\subsubsection{Las causas específicas de exoneración.}

Las causas específicas de exoneración son más numerosas.

En efecto, el productor no se responsabilizará de pleno derecho si demuestra ${ }^{45}$ :

$1^{\circ}$ Que no había puesto el producto en circulación (que es la hipótesis del robo en la fábrica o en la tienda, por ejemplo);

$2^{\circ}$ Que el defecto causante del daño no existía en el momento en que puso el producto en circulación, o que dicho defecto nació posteriormente;

39 Ver, por ejemplo, Cass. civ. 1 ère, 24 janv. 2006, n03-20.178; JCP G 2006, II, 10082, note L. GRYNBAUM; JCP G 2006, I, 166, n4, obs. Ph. STOFFEL-MUNCK; rec. Dalloz 2006, 1273, note C. NEYRET; rec. Dalloz 2006, 1931, obs. P. JOURDAIN; RDC 2006, 841, obs. J.-S. BORGHETTI; RTD civ. 2006, 323, obs. P. JOURDAIN; Cass. civ. 1 ère, 22 mai 2008, Bull. civ. 2008, I, nº147 y ss.; Cass. civ., 9 juill. 2009 , Bull. civ. 2009, I, n¹76; Cass. civ., 23 sept. 2009, Bull. civ. 2009, I, nº188.

40 Art. 1245-7 C. civ.; Cass. civ. 1 ère, 26 nov. 2014, n¹3-18.819; RDC 2015, 252, note G. VINEY; rec. Dalloz 2015, 405, note J.-S. BORGHETTI; JCP G 2015, doctr. 740, note L. BLOCH; Cass. civ. $1^{\text {ère }}, 15$ mars 2017, n¹5-27.740.

41 Art. 1245-17 C. civ.; Cass. civ. 1 ère, 17 mars 2016, n¹3-18.876; RDC 2016, 442, note J.-S. BORGHETTI; RTD civ. 2016, 646, obs. P. JOURDAIN; rev. Resp. civ. et assur. 2016, comm. 158, D. BAKOUCHE; rec. Dalloz 2017, 24, obs. Ph. BRUN.

42 Art. 1245-14 C. civ.; Ph. BRUN, op. cit., n753 y sig.

43 Art. 1245-12 C. civ.; Cass. civ. 1 1e, 7 nov. 2006, n05-11.604; Contrats, conc., consom. 2007, 60, note G. RAYMOND; Contrats, conc., consom. 2007, 64, note L. LEVENEUR.

44 Art. 1245-13 C. civ.

45 Art. 1245-10 C. civ.

COUARD, JULIEN. La responsabilidad por los daños causados por productos defectuosos: Aspectos de derecho francés. Revista Justicia y Derecho, Santiago, v. 1, n 1, 2018 
$3^{\circ}$ Que el producto no estaba destinado a la venta o a cualquier otra forma de distribución;

$4^{\circ}$ Que, en el momento en que puso el producto en circulación, el estado de los conocimientos científicos y técnicos no permitía la detección del defecto (tenemos aquí un terreno fértil para el juez en cuanto a su evaluación del estado de los conocimientos en un momento determinado ${ }^{46}$ );

$5^{\circ} \mathrm{O}$, por último, que el defecto se debía a la conformidad del producto con normas imperativas de carácter legislativo o reglamentario: nemo censetur ignorare legem (la ley se presume conocida por todos) incluida la víctima.

\section{Conclusión}

Podemos decir que en Francia tenemos un régimen equilibrado entre los intereses de seguridad jurídica del productor y de protección e indemnización de los usuarios de productos que permitió liberarse de las dudas nacidas con el tiempo a propósito de los textos originales del Código civil, pero sin abolirlos, porque todavía conservan toda su utilidad.

Es interesante constatar que el proyecto de reforma sobre la responsabilidad, presentado en marzo $2017^{47}$, no prevé modificaciones en cuanto a la responsabilidad derivada de productos defectuosos ${ }^{48}$.

\section{Bibliografía}

\section{Libros y artículos.}

O. AKYUREK y C. PHILIBERT (2017), «Avant-projet de loi portant réforme de la responsabilité civile et responsabilité du fait des produits défectueuX», Les Petites Affiches, n¹25: p. 18.

M. BACACHE-GIBEILI, Les obligations, la responsabilité civile extracontractuelle, $3^{\text {ème }}$ - éd., Economica, Traité de droit civil (C. Larroumet, dir.), tome 5, janv. 2016, 1, 104 p.

O. BERG, «La notion de risque de développement en matière de responsabilité du fait des produits défectueux», JCP G 1996, l, 3945.

L. BLOCH, «Pour une autre présentation de responsabilité du fait des produits de santé défectueux», rev. Resp. civ. et assur. 2009/12, p. 7.

46 O. BERG, «La notion de risque de développement en matière de responsabilité du fait des produits défectueuX», JCP G 1996, I, 3945; I. VEZINET, «Le risque de développement en matière de responsabilité du fait des produits défectueuX», Dr. et Patrimoine 1997, p. 54; J. CALAIS-AULOY, «Le risque de développement: une exonération contestable», in Mélanges Cabrillac, Litec, 1999, p. 81; C. LARROUMET, «La notion de risque de développement, risque du XXlème siècle», in Clés pour le siècle, Dalloz 2000, p. 1589; P. OUDOT, Le risque de développement. Contribution au maintien de la réparation, Thèse, Dijon, 2001; J.-S. BORGHETTI, La responsabilité du fait des produits défectueux, Etude de droit comparé, ob. cit., n402 y ss; CJCE, 29 mai 1997, aff. 300/95, Commission contre Royaume-Uni; rec. Dalloz 1998, 488, note A. PENNEAU; Corte de Apelaciones de Toulouse, 22 févr. 2000, JCP G 2000, II, 10429, note Ph. le TOURNEAU.

47 RLDC oct. 2017, n¹57 supplément.

48 O. AKYUREK et C. PHILIBERT, «Avant-projet de loi portant réforme de la responsabilité civile et responsabilité du fait des produits défectueux», Les Petites Affiches, 23 juin 2017, n¹25, p. 18. 
J.-S. BORGHETTI, La responsabilité du fait des produits défectueux, Etude de droit comparé, ob. cit., p. 402 y ss. J.-S. BORGHETTI, La responsabilité du fait des produits défectueux, Etude de droit comparé, LGDJ, Bibl. de droit privé, tome 428, 2004, 784 p.

M. BORGETTO et alii, «La responsabilité du fait des produits de santé défectueuX», RDSS 2008, p. 1005.

V. BOUQUET y E. FOUASSIER, «Le projet de réforme de la responsabilité civile et les produits de santé», rec. Dalloz 2017, p. 834.

Ph. BRUN, Responsabilité civile extracontractuelle, 4ème éd., Lexis Nexis, coll. Manuels, nov. 2016, 674 p.

J. CALAIS-AULOY, «Le risque de développement: une exonération contestable», in Mélanges Cabrillac, Litec, 1999, p. 81.

H. CAPITANT, F. TERRÉ et Y. LEQUETTE, Grands arrêts de la jurisprudence civile, Dalloz, tome 2, 12 ème éd., 2008, p. 389.

CHAMBRAUD, «La difficile introduction de la directive sur la responsabilité du fait des produits défectueux en droit français», Rev. europ. dr. de la consommation, 1997/3, p. 169.

L. CLERC-RENAUD, «Quelle responsabilité en cas de dommages causés par des produits de santé?», RLDC 2007/1, p. 15.

J.-Ph. CONFINO, «La mise en circulation dans la loi du 19 mai 1998 sur la responsabilité du fait des produits défectueux», Gaz. Pal., 2 févr. 2001, n³3, p. 2 y 22 avr. 2001, p. 2.

R. A. EPSTEIN, Theory of Strict Liability: Toward a Reformation of Tort Law, Cato Institute, 1979, 141 p.

Y. DAGORNE-LABBE, «La loi du 19 mai 1998 relative à la responsabilité du fait des produits défectueuX», Defrénois 1998, p. 1265.

J. GHESTIN, «Le nouveau Titre IV bis du Livre III du Code civil 'De la responsabilité du fait des produits défectueux'. L'application en France de la directive sur la responsabilité du fait des produits défectueux après la loi n98-389 du 19 mai 1998», JCP G 1998, I, p. 148.

S. JOLY, «La nouvelle génération des doubles délais extinctifs», rec. Dalloz 2001, chron. 1450.

P. JOURDAIN, «Commentaire de la loi n98-389 du 19 mai 1998 sur la responsabilité du fait des produits défectueux», JCP E 1998, 1204.

P. JOURDAIN et A. GUEGAN-LECUYER (dir.), «La responsabilité du fait des produits défectueux, 30 ans après la directive», rev. Resp. civ. et assur. 2016, dossier spécial.

Y.-M. LAITHIER, T. GENICON et O. DESHAYES, Réforme du droit des contrats, du régime général et de la preuve des obligations: Commentaire article par article, Lexis Nexis, oct. 2016, 945 p.

LARROUMET, «La responsabilité du fait des produits défectueux après la loi du 19 mai 1998», rec. Dalloz 1998, p. 311.

LARROUMET, «La notion de risque de développement, risque du XXI ${ }^{\text {ème }}$ siècle», in Clés pour le siècle, Dalloz 2000, p. 1589.

M. LATINA et G. CHANTEPIE, La réforme du droit des obligations - Nouveauté: Commentaire théorique et pratique dans l'ordre du Code civil, Dalloz, juin 2016, 1104 p.

Ph. Le TOURNEAU (dir.), Droit de la responsabilité et des contrats, 11 ème éd., Dalloz Action, nov. 2017, 2760 p.

L. LEVENEUR, «Le défaut», in «La responsabilité du fait des produits défectueux», Les Petites Affiches, 28 déc.

COUARD, JULIEN. La responsabilidad por los daños causados por productos defectuosos: Aspectos de derecho francés. Revista Justicia y Derecho, Santiago, v. 1, n 1, 2018 
1998, numéro spécial, p. 28.

M. MEKKI (coord.), Avant-projet de réforme du droit de la responsabilité civile: l'art et la technique du compromis, Lextenso, nov. 2016, 186 p.

B. MERCADAL, Réforme du droit des contrats, éd. Francis Lefebvre, mai 2016, 408 p.

P. OUDOT, Le risque de développement. Contribution au maintien de la réparation, Thèse, Dijon, 2001.

G. RAYMOND, «Premières vues sur la loi n98-389 du 19 mai 1998 sur la responsabilité du fait des produits défectueux», Contrats, conc., consom. 1998, chronique $n^{\circ} 7$.

RIPERT; rec. Sirey 1941, I, 217, note L. MAZEAUD ; JCP 1942, II, 1766, note J. MIHURA.

J. ROCHFELD, «Les ambiguïtés des directives d'harmonisation totale: la nouvelle répartition des compétences communautaire et interne (à propos de l'arrêt de la CJCE du 4 juin 2009) «, rec. Dalloz 2009, p. 2047.

Ph. STOFFEL-MUNCK, JCP G 2007, I, p. 185.

F.TERRÉ (dir.), Pour une réforme du droit de la responsabilité civile, Dalloz, coll. Thèmes et commentaires, nov. $2011,238 \mathrm{p}$.

J. TRAULLÉ, «Responsabilité du fait des produits défectueux - Les dommages réparables», rev. resp. civ. et assur. 2016, dossier 4.

VEZINET, «Le risque de développement en matière de responsabilité du fait des produits défectueux», Dr. et Patrimoine 1997, p. 54.

G. VINEY, «L'introduction en droit français de la directive européenne du 25 juillet 1985 relative à la responsabilité du fait des produits défectueuX», rec. Dalloz 1998, 291.

G. VINEY y P. JOURDAIN, Les régimes spéciaux et l'assurance de responsabilité, $4^{\text {ème }}$ éd., LGDJ, Traité de droit civil (J. Ghestin, dir.), nov. 2017, 688 p.

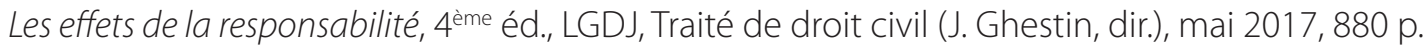

\section{Jurisprudencia (por orden de citación)}

CJCE, 25 avril 2002, Commission des Communautés Européennes contre République française, affaires jointes C-52/00, C-154/00 C-183/00; Contrats, conc., consom. 2002, n¹1, p. 4-5, obs. C. LAPORTE.

Cass. civ. 1ère, 20 sept. 2017, n¹6-19643; JCP G 2017, 1186, note J.-S. BORGHETTI; Cass. civ. 1 ère, 18 oct. 2017, n¹5-20791; JCP G 2017, 1220, note G. VINEY.

Cass. ch. réunies, 2 déc. 1941, rec. Dalloz critique 1942, 25, rapport LAGARDE et note G.

CJCE, 9 févr. 2006, O’Byrne, rev. europ. dr. de la consommation, 2005/4, p. 352, note V. PIRE; JCP G 2006, I, 166, n¹4, obs. Ph. STOFFEL-MUNCK; rec. Dalloz 2006, 1934, obs. Ph. BRUN.

Cass. civ. 1 ère, 24 janv. 2006, n03-20.178; JCP G 2006, II, 10082, note L. GRYNBAUM; JCP G 2006, I, 166, n4, obs. Ph. STOFFEL-MUNCK; rec. Dalloz 2006, 1931, obs. P. JOURDAIN; RDC 2006, 841, obs. J.-S. BORGHETTl; RTD civ. 2006, 323, obs. P. JOURDAIN.

Cass. civ. 1 ère, 5 avr. 2005, JCP G 2005, I, 149, n5, obs. G. VINEY; JCP G 2005, II, 10085, note L. GRYNBAUM. Cass. civ. $1^{\text {ère }}, 21$ juin 2005, Bull. civ. 2005, I, n²75.

Cass. civ. 1ère, 24 janv. 2006, Bull. civ. 2006, I, n³5.

COUARD, JULIEN. La responsabilidad por los daños causados por productos defectuosos: Aspectos de derecho francés. Revista Justicia y Derecho, Santiago, v. 1, n 1, 2018 
Cass. civ. $1^{\text {ère }}, 7$ nov. 2006, Bull. civ. 2006, I, n467.

Cass. civ. 1 ère, 22 nov. 2007, JCP G 2008, l, 125, nº, obs. Ph. STOFFEL-MUNCK.

CJCE, 4 juin 2009, aff. C-285/08, Moteurs Leroy Somer : JurisData n²009-007423; JCP G 2009, 82, P. JOURDAIN; RDC 2009, 1381, note G. VINEY; RDC 2009, 1448, note C. AUBERT DE VINCELLES; rec. Dalloz 009, 1731, note J.-S. BORGHETTI; rec. Dalloz 2010, 49, obs. O. GOUT; RTD civ. 2009, p. 738, obs. P. JOURDAIN.

Cass. civ. 1 ère, 24 janv. 2006, n03-20.178; JCP G 2006, II, 10082, note L. GRYNBAUM; JCP G 2006, I, 166, n²4, obs. Ph. STOFFEL-MUNCK; rec. Dalloz 2006, 1273, note C. NEYRET; rec. Dalloz 2006, 1931, obs. P. JOURDAIN; RDC 2006, 841, obs. J.-S. BORGHETTI; RTD civ. 2006, 323, obs. P. JOURDAIN.

Cass. civ. 1 1're, 22 mai 2008, Bull. civ. 2008, I, n¹47 y ss.

Cass. civ., 9 juill. 2009, Bull. civ. 2009, I, n¹76.

Cass. civ., 23 sept. 2009, Bull. civ. 2009, I, n¹88.

Cass. civ. 1 ère, 26 nov. 2014, n¹3-18.819; RDC 2015, 252, note G. VINEY; rec. Dalloz 2015, 405, note J.-S. BORGHETTI; JCP G 2015, doctr. 740, note L. BLOCH.

Cass. civ. $1^{\text {ère }}, 15$ mars 2017, $n^{\circ} 15-27.740$.

Cass. civ. $1^{\text {ère }} 17$ mars 2016, n¹3-18.876; RDC 2016, 442, note J.-S. BORGHETTI; RTD civ. 2016, 646, obs. P. JOURDAIN; rev. Resp. civ. et assur. 2016, comm. 158, D. BAKOUCHE; rec. Dalloz 2017, 24, obs. Ph. BRUN.

Cass. civ. $1^{\mathrm{èr}}$, 7 nov. 2006, n05-11.604; Contrats, conc., consom. 2007, 60, note G. RAYMOND; Contrats, conc., consom. 2007, 64, note L. LEVENEUR.

CJCE, 29 mai 1997, aff. 300/95, Commission contre Royaume-Uni; rec. Dalloz 1998, 488, note A. PENNEAU. Corte de Apelaciones de Toulouse, 22 févr. 2000, JCP G 2000, II, 10429, note Ph. le TOURNEAU. 